\title{
Education, Information Literacy and Lifelong Learning: Three Pillars of Nation Building in the Emerging Knowledge Society
}

\author{
Jagtar Singh ${ }^{1}$ \\ and \\ Dilara Begum ${ }^{2}$
}

\begin{abstract}
This paper is based on the assumption that libraries have a pivotal role to play in nation building, and future of libraries is in our own hands. It further emphasizes the need for change in libraries in the context of emerging knowledge economy. It makes reference to the United Nations' Millennium Development Goals, UNESCO's Education for All Programme (EPAP), and Information for All Programme (IFAP), as well as the mandate of the National Knowledge Commission (NKC). It also highlights the impact of ICT on the life and work of people, and paradigm shift in libraries. It emphasizes that library consortia, institutional repositories, and open access archives are strategic response to the paradoxical situation of growing digital documents and declining library budgets. It further explains that more important than the name of a library (traditional or digital) is the mandate and the context of the library. It also enlists the challenges and opportunities facing libraries, and concludes that the future of libraries is though uncertain, yet in our own hands.
\end{abstract}

Keywords: Information Literacy, Knowldge Society, Lifelong learning.

Education liberates people from darkness and empowers them with knowledge, competencies, and attitudes to become assets for human progress across frontiers. That is why every nation puts premium on education to take its people to next level of consciousness. Taking cognizance of this fact, United Nations (UN) has set up the following seven Millennium Development Goals to be achieved by the year 2015 .

Goal 1: Eradicate extreme poverty and hunger

Goal 2: Achieve universal primary education

Goal 3: Promote gender equality and empower women

${ }^{1}$ Professor and Head, Department of Library and Information Science, Punjabi University, Patiala (Punjab) India, Email: jagtar.kindu@gmail.com

${ }^{2}$ Joint Librarian, Head of Library, East West University, Dhaka, Bangladesh, Email: dilara@ewubd.edu 
Goal 4: Reduce child mortality

Goal 5: Improve maternal health

Goal 6: Combat HIV/AIDS, malaria and other diseases, and

Goal 7: Ensure environmental sustainability

UNESCO also has two ambitious programmes namely, Education for All Programme (EPAP) and Information for All Programme (IFAP) to spread education among member nations, and provide access to information to one and all. Education, information literacy, and capacity building are the thrust areas for the UNESCO. In India, the Prime Minister has constituted a National Knowledge Commission (NKC) in the year 2005 under the Chairmanship of Mr. Sam Pitroda who brought telecommunication revolution in India. The NKC is focusing on expansion and excellence of higher education, and inclusion of left out categories in the field of higher education. The National Knowledge Commission is basically concerned with the following five key areas:

Access to knowledge; Knowledge concepts; Creation of knowledge; Knowledge applications, and Delivery of services

India is the first country in the world to establish a National Knowledge Commission (NKC) with a view:

1. To build excellence in the education system to meet the knowledge challenges of the $21^{\text {st }}$ century and increase India's competitive advantage in fields of knowledge;

2. To promote creation of knowledge in science and technology institutions and laboratories;

3. To improve the management of institutions working on intellectual property rights;

4. To promote knowledge applications in agriculture and industry; and

5. To promote the use of knowledge capabilities in making government an effective, transparent and accountable service provider to the citizens, and promote wide spread sharing of knowledge to maximize public benefit.

In its recommendations submitted to the Prime Minister of India, the NKC has recommended the opening of 1500 more universities by the year 2015 to enhance Gross Enrolment Ratio (GER) to 15\%, and also set up a National Commission on Libraries to provide massive access to quality information in a cost effective manner. The education budget has been increased three fold, and Rs. 10, 000 million have been promised to improve the library and information infrastructure in India. These recommendations and promises will certainly go a long way to improve the quality of life and work of people all across India. But unfortunately, about 300 million people in India are illiterate and similar number of people is living below poverty line. In spite of all these efforts by India, the digital divide between the haves and have nots is increasing day by day.

\section{Paradigm Shift}

Information and communication technology (ICT) has made a deep impact on all types of libraries. Today we are talking about the power of digital and virtual libraries. At the same time 


\section{Bangladesh Journal of Library and Information Science}

we are very much worried about the future of libraries in general and academic libraries in particular. But we would like to emphasize that the future of libraries is dependent both on external and internal changes. The ICT is providing the library and information professionals (LIPs) with both opportunities and challenges. There is a paradigm shift from standalone libraries to library and information networks; from printed publications to digital documents; and from ownership to access. This transition is the result of the impact of ICTs, the Internet and the web on different types of libraries.

If we look around, many educational, social, economic, cultural, political, and technological changes are taking place. In the context of libraries and information centers (LICs), economic and technological changes have made a profound impact. Economically speaking, LICs are faced with a diametrically opposite situation with growing electronic resources and services on the one hand, and declining library budgets and library use on the other. There is a tremendous pressure on the library and informational professionals (LIPs) to justify the need for their existence in view of the fact that the library users are moving away from the libraries. It is high time to take stock of the things, why this is happening and what is the way out to bring back the users to the fold of libraries.

Basically, the future of libraries is in the hands of library users. Unfortunately, the end-users have fallen in the hands of commercial database providers and search engines like Google. The Net Generation thinks that Google has answer to all their queries. That is not true, and at stake is the quality of information and future of libraries. There is an immediate need to turn the rote learners into independent learners and critical thinkers. The challenge for today's teachers, including librarians, is to effectively educate students on how to strategically gather information from the Internet and other sources in ways that yield the best sources in a minimal amount of time. To develop into professional information managers, students must learn information skills for effective searching. Students need to move beyond their academic assignments for being able to complete research for the world of work. If universities are to prepare graduates to be world-class professionals, then we must place information literacy skills at the core of instruction in every discipline. This can best be accomplished when librarians in collaboration with classroom faculty infuse information literacy instruction into and across the curriculum.

\section{Strategic Response}

The organization culture, library leadership and trained library personnel play a pivotal role in determining the role and status of libraries. LIPs are faced with a diametrically opposite situation with growing electronic resources on the one hand, and declining library budgets on the other. This has led to a paradoxical situation of paucity in plenty. There is a lot of unreliable information on the web in the public domain. LIPs are required to learn the art of finding needle from the hay stack. It is a profound challenge as the haystack is growing and the needle is moving from time to time. Information literacy is the way out to manage chaos on the web and ensure end-user satisfaction. Shared subscription, library consortia, institutional repositories, and open access archives are the outcome of our strategic response to deal with the challenge of declining library budgets. Instead of worrying about the future of libraries, we 
must learn to do the gap analysis and the SWOT analysis. We are required to ask a question from ourselves. The question is "Why the end-user is going to the Google by leaving behind the library?" Perhaps we have failed to come up to the expectations of the end users. The effectiveness of library service lies at the point where the horizontal and vertical lines cross each other. In other words, where there is the perfect matching of end users' information needs, and library and information professionals' competence to meet those needs. Are we doing that? We must put this question to ourselves, and we will get a perfect answer to our worries about the future of libraries. For bright future, the LIPs must identify with the end-users.

Library and Informational Professionals (LIPs) are not sitting silently with their fingers crossed. Library consortia, institutional repositories, knowledge repositories, open source software, and open source gateways are the strategic responses being adopted by the LIPs across the globe to provide instant access to pertinent information to stakeholders in a costeffective and timely manner. And they are fairly successful also.

\section{Library Consortium in India and Bangladesh}

The UGC-Infonet Digital Library Consortium was formally launched in December 2003 by Honourable Dr. A P J Abdul Kalam, the then President of India. The Consortium proved to be a recipe to university libraries, which have been discontinuing subscription of scholarly journals because of "Serials Crisis". The Consortium provides current as well as archival access to more than 5000 peer-reviewed journals and eight bibliographic databases from 23 publishers and aggregators in different disciplines. The programme has been implemented in a phased manner. In the first phase that began in 2004, access to e-resources was provided to 50 universities who had Internet connectivity under the UGC-Infonet Connectivity programme of the UGC. In the second phase, 50 more universities were added to the programme in the year 2005. So far 150 universities out of 171 that come under the purview of the UGC have been provided differential access to e-resources subscribed by the Consortium. These e-resources covers almost all subject disciplines including arts, humanities, social sciences, physical sciences, chemical sciences, life sciences, computer sciences, mathematics, statistics, etc and other subject areas are to be added in near future. The programme is wholly funded by the UGC and executed by the INFLIBNET Centre. The benefit of subscription to e-resources would also be extended to the colleges, to begin with the Colleges for Potential with Excellence (CPE) and autonomous colleges. The Consortium also plans to launch its "Associate Membership Programme" wherein private universities and other research organization would be welcomed to join the Consortium for selected eresources. (Trivedi, 2009)

In Bangladesh, a Memorandum of Understanding (MoU) was singed with Bangladesh Academy of Science (BAS) and International Network for the Availability of Scientific Publications (INASP) in the year 2006. Consequently, Bangladesh INASP-PERI Consortium (BIPC) was formed with the Primary Contact Officers of the participating organizations. In this way Bangladesh became a member of the consortium network. Through this network a large number of journals of world renowned publishers are made available to Bangladesh. An 


\section{Bangladesh Journal of Library and Information Science}

on-line journal network under the Program for Enhancement of Research Information (PERI) started in 2006 on trial basis free of subscription. From January 2007, Bangladesh started subscribing PERI/INASP and 13 organizations paid subscription for the network for an amount of US\$ 67,000. In 2008, the number of members rose to 22 and the network paid US\$ 87000 to INASP. By last year, more than 30 organizations joined the network and more organizations are showing interest to join because of the immense benefit received in a costeffective manner. The subscription paid to INASP by now is in the tune of US\$1,60,000.

\section{Features of Digital Resources}

But the most important challenge is to sensitize the stakeholders about the availability of the digital resources which are very useful in nation building. Digital resources are not substitutes to the analog resources and services. Rather they are supplementing the physical paradigm of preservation of, and access to our documentary heritage. Digital resources and services available via the Internet have given a death blow to the traditional constraints of space and time. Instant information access is available to anyone, anywhere at any time provided pertinent information is available, accessible and affordable. Digital resources and time and space effective and preservation of and access to documentary at risk is also possible via digital preservation. Repackaging and instant simultaneous searching and access are the added advantages. Effective e-learning and library outreach has been made possible only by the digital resources and services

\section{Information Skills for Learning}

For making use of these digital resources and services, information seekers and library users are required to develop certain habits and attitudes along with acquiring a set of information skills for learning. According to UNESCO Report, "Learning: The Resource Within", there are four pillars of learning as given below:

1. Learning to know

2. Learning to do

3. Learning to be, and

4. Learning to live together

Learning to know means that the stakeholders must have sound knowledge of philosophical and theoretical foundations of the subject; learning to do means active learning or learning by doing; whereas learning to be means learning to be a face in the crowd or being a competent person; and learning to live together means developing a shared vision and internalizing a team spirit. In fact, real learning cannot take place unless students value the learning they receive. Thus, universities must change students' attitudes toward the Internet. Faced with a generation of learners who believe books are an obsolete tool of learning and that libraries are merely book repositories, librarians and faculty must persuade young researchers to recognize the perils of using the Internet without a filter of critical thinking to determine the reliability and validity of the information they gather from the World Wide Web. Basically books provide us the comfort of companionship and luxury of solitude. Unlike TV and the Internet, books and radio are a hot medium as they fire our imagination. 


\section{Challenges and Opportunities}

With the ascent of digital documents and digital libraries, library and information professionals' role has expanded and challenges have increased many fold. These challenges relate to collection management, knowledge organization, digital preservation, online searching, content management, knowledge management, and promoting the use of libraries and networks. LIPs are required to work as leaders, managers, and facilitators. The ICT and the Internet has thrown open the doors to the LIPs to many opportunities. Now $24 \times 7 \times 365$ access to information is available and the library is becoming a private place instead of a public space. LIPs have the opportunity to provide global reach to the indigenous knowledge. Similarly, we can get access to world's knowledge and information through the Internet, provided we have the will, skill, and the appropriate attitude. These opportunities and challenges can be handled effectively by competent library personnel. Sound knowledge base, pertinent skills and pro-active positive mind set are the essential components of a competent library and information professional. Do we have that? If not, then the future of libraries is certainly uncertain. If yes, then there is no reason to worry about the future of libraries. In fact, we must develop employable skills among the budding library professionals. Library and information courses must be consistent with the job market.

\section{Change Management}

According to Peter Senge, following five factors can go a long way to enable people to manage change and stay ahead of time:

\section{Systems thinking \\ 2. Shared vision \\ 3. Positive and open mindset \\ 4. Personal mastery, and \\ 5. Team learning.}

It's a well known fact that value of knowledge and information lies in use. Hence most important challenge today is to create awareness of knowledge resources with particular focus on digital resources and services. Information literacy can serve as a critical tool to facilitate learning that is a lifelong process. Learning is not an end in itself; rather it is a journey towards socio-economic development and human progress. Information literacy is the tool to enable the end-users to become independent learners and critical thinkers. But unfortunately the concept of and practice of information literacy, as well as the spirit of service has not gained ground to the desirable level across frontiers. We are trying to process the multidimensional universe of knowledge and information with unidirectional mind-set. The technology is developing at the rocket speed and our mind-sets are moving at mule's speed. We are trying to process the $24 \times 7$ phenomenon with a $9 \times 5$ mind-set. That is the root cause of many of our problems.

\section{Pressures for Change}

Like other stakeholders across frontiers, library and information professionals are also under tremendous pressure to manage change in libraries and information centres. There are both 


\section{Bangladesh Journal of Library and Information Science}

external and internal pressures. Externally, the ICT, the Internet, the Google, and the commercial information providers are giving fierce competition to libraries and library personnel. Internally, organizational culture, declining library budgets, and lethargic and apathetic attitude of majority of LIPs to change are the critical factors for the present state of the art. The end result is that the end-users are moving away from libraries and getting carried away by the commercial publishers and search engine like Google. It is high time that LIPs adopt a pro-active attitude, internalize team spirit, develop professional and personal competencies, and learn to be a face in the crowd of information providers. Librarians are the best professionals to organize knowledge and information to save the time of the information seekers. There is a lot of chaos in the public domain on the web. Librarians are required to retrieve pertinent information from the web, consolidate and repackage it for the benefit of the end-users. In the digital age, customization and personalization of information is the heart of the matter. That can be done in a professional way by LIPs by using the best professional practices, such as library classification, library cataloguing, concept indexing, bibliographical control, and vocabulary control. But for doing that LIPs must be on sound footing with regard to the philosophy of library and information science, its theoretical foundations, and best practices.

\section{Areas for Change}

The work of libraries has always been organized around the flow of information. Generation, acquisition, processing, storage, dissemination, and use are the six stages of information life cycle. Barring the first and the last stages, libraries and librarians are directly concerned with the other four stages of information life cycle. All these four areas have been profoundly affected by the ICTs. In this context, change must be managed in the following functional areas in libraries and information centres:

Library outreach; Reader services; Collection development and management; Library automation and networking; Technical services; Library building; Library finance, and Library personnel

\section{Leadership Competencies}

There is great difference between a leader and a manager, as well as competence and competencies. A leader facilitates change but a manager maintains the status quo. Similarly, competence means mastery and competencies means a set of skills. These can be hard as well as soft skills. Competence comes with experience. But before that we must have a good commonsense and formal education. Then strategic professional learning must be internalized by the LIPs as a lifelong learning process. LIPs must be equipped with cultural literacy and information skills for learning. Similarly, a sense of responsibility and accountability along with team spirit, motivation, and interpersonal skills should also become a part of their mind, body, and soul. Only that way, the LIPs can make sense of the web-based chaos. Here one is reminded of the lines by T.S. Elliot:

Where is the wisdom we have lost in knowledge?

Where is the knowledge we have lost in information? 


\section{Bangladesh Journal of Library and Information Science}

LIPs must learn to identify the domains of data, information, knowledge, and wisdom. Data are stray facts in context, information is meaningful data and eliminates uncertainty and facilitates decision making. Knowledge helps in problem solving, and wisdom warns us about the consequences of our decisions and actions. Library leaders are also required to promote the use of knowledge and information. The Five Laws of Library Science by Dr. Ranganathan are more relevant in the digital age where there is a lot of information deluge around the end-users. Information seekers are having more and more of everything but less and less of time. Ranganathan advises LIPs to save the time of the readers. Personalization is the only way out as information needs are highly personal. These needs vary from person to person, place to place and time to time. A reader requesting a dictionary is not interested in the whole dictionary; rather he is interested in the meaning of a particular word. Do we have that attitude to serve the library user with that meaning? We must ask this question to ourselves. Perhaps we will get the answer and change our attitude. Today, the information seeker is overwhelmed by the webbased chaos and the following line by Coleridge represents the bewildered end-user:

\section{Water water everywhere, but not a drop to drink}

We must ask ourselves a question that are we competent to provide the end-user with that drop of water in the form of pertinent information? We put this question to you to find a suitable answer. LIPs must commit themselves to bridge the widening gap between the 'info-rich' and the 'info-poor' on the one hand and the growing gap between the 'tacit knowledge' and the 'explicit knowledge' on the other hand. For this, LIPs will have to develop a critical and positive outlook, as well as a learning attitude to add value to their resources and services.

\section{Conclusion}

The real power of any nation is not its money or natural resources; rather it lies with its human resources. Hence a nation that puts premium on its human resources is bound to lead other nations. Similarly the value of knowledge and information lies in use. Education, information literacy and lifelong learning are the three pillars for putting knowledge to work. Libraries and information networks have a pivotal role to play in human progress by preserving and serving knowledge and information across frontiers. Library and information professionals must leave no stone unturned to develop hybrid libraries that are user-centred and expert-assisted. Preservation of our documentary heritage is the hallmark of librarianship. Hence too much bias in favour of buying access from the commercial providers as well as too much dependence on the Internet and the Google for information is not good in the long run. If something goes wrong with the Internet or Google starts charging for its use, we will be in a thick use. If we are really committed to nation building then we must not promote the interests of commercial information providers at the cost of our libraries that are basically service agencies. 


\section{Bangladesh Journal of Library and Information Science}

\section{References}

Bangladesh INASP-PERI Consortium

http://www.bas.org.bd/bangladesh-inasp-peri-consortium.html (Accessed on 26 Dec. 2009)

India. National Knowledge Commission (NKC)

www.knowledgecommission.gov.in/ (Accessed on 26 December 2009)

Jagtar Singh. Digital library of the future: promises, perils and models. In: Knowledge, library and information networking (NACLIN 2009), edited by H.K. Kaul and V.K. Anand. New Delhi: DELNET, 2009, pp. 1-12.

Senge, Peter M. The fifth discipline: the art and practice of the learning organization. New York: Currency Doubledat, 1994.

Trivedi, Kruti, Suresh Chauhan and Jagdish Arora. Economics of UGC-INFONET Digital Library Consortium. In: Library and Information Science in Digital Age: Essays in Honour of Prof. M.P. Satija (V.1.), edited by Jagtar Singh, Indervir Malhan and Trishanjit Kaur. New Delhi: Ess Ess Publications, 2009, p. 358.

UNESCO. Education for All Programme (EFAP)

www.apc.org/en/.../unescos-education-all-programme-put-icts-practice (Accessed on 26 December 2009)

UNESCO. Information for All Programme (IFAP)

portal.unesco.org/.../ev.php-URL_ID =1627\&URL_DO=DO_TOPIC\&URL_SECTION= 201.html

(Accessed on 26 December 2009)

UNESCO. Learning: The Treasure Within

www.unesco.org/education/educprog/lwf/dl/learning2020.pdf (Accessed on 26 Dec. 2009)

UN Millennium Development Goals

www.un.org/millenniumgoals/ (Accessed on 26 December 2009) 